\title{
Interface design and contemporary: human creating new guidelines for high-tech products
}

\author{
Andreia Salvan Pagnan, Giovana Freitas Rabelo Ribeiro, Maria Goretti Souza Gonçalves, Jairo José \\ Drummond Câmara* and Sandra Motta Baptista \\ CPqD, University State of Minas Gerais, Presidente Antônio Carlos Avenue, 4575, São Luiz, Belo Horizonte, \\ Minas Gerais, Brazil
}

\begin{abstract}
Contemporary electronic industry offers a wide range of products. Usually touch sensitiveand with few buttons and a lot of functions these products not always have a friendly interface. The human $\mathrm{x}$ design interface based on electronics' ergonomics is the focus of this research. An evolutionary analysis of the electronics industry design within a contemporary context clarifies this relation and proposes new guidelines for a more conscious design.
\end{abstract}

Keywords: design, technology, man

\section{Introduction}

The interactive relationship between modern man and the modern equipments' technology created by the contemporary design creates an interface that raises queries regarding the ergonomic factors of technology products offered by the market. Respect for the human being as a whole should be the starting point for designing a new product. In man's interaction with the product are involved in their skills, which are divided into three levels: cognitive, perceptual-motor and emotional skills. In other words: knowing, doing and feeling [4]. An evolutionary analysis of what the electronics industry has been offering through the past ten years and how contemporary human interacts with such equipments allows the creation of new guidelines for a more focused design for usability. The task of these industries is to create the best mice and keyboards with more features, sharper displays, touch screens, motion-sensing games and many other developments meeting the needs of a society where miniaturization and minimalization of phones and i-phones contrasts with the maximalism of televisions. It is not the technology that presents the challenge, but mostly the way we use it. With this speech we look for a friendly design not necessarily easy to handle, but that establishes friendship between consumer and product. It is proposed an abandonment of the adding extra ${ }^{*}$ functions to products obsession towards an increase of consumer experience quality.

\section{The user $x$ product interaction}

The interface created between the user and the product involves multi-factors. Among them lies the ergonomic factor of the product. This creates the need for a new design leading to new lines of research where new strategies emerge as clean cycles, assemblydisassembly, durability, miniaturization and

\footnotetext{
*orresponding author: camara.jairo@gmail.com
} 
minimalization, the breadth of use and service line. The design should be rethought as a multidisciplinary organization developing relevant qualities to new products. It is necessary to include two additional levels of human-machine interaction: perceptual-motor skills and emotional skills. The perceptual-motor skill is that one when people perceive their senses and what they can do with their bodies, requiring physical interaction, manipulating objects instead of icons on a screen. This perception fits nicely on the latest trends in humancomputer interaction (HCI). The emotional skills are source of study of MIT's Media Lab, which conducted the study of "affective computing". In the first conference on Emotional Design [9] it reports that emotion comes on stage not only in academy but also in industry. Some automotive industries finance the college's project 'projecting emotion" in which an instrument was developed to measure the emotional reactions of people in cars [10] cited in [3].

How can the designer integrate an innovative product that enhances cognitive skills, perceptual-motor and emotional skills? This problem can be solved by focusing on user experience while fully respecting all his skills. The designer must create a context for the experience rather than just a product. He should probe the experiential world of the user. It is the designer' task make the function of the product accessible to the user, which should experience the access to the product as having a pleasant experience to handle it [10] cited in [6].

\section{The era of interactive design}

Touch screen development began in the lates 60 's. The touch screen was first seen at the 2006 TED conference, presented by Jeff Han. Since then, manufacturers of electronic equipment have been engaged in producing equipment using gestural interaction [12]. What was once just a feature to make life easier for users of ATMs and check-in terminals at airports spread to portable electronics shortly after the launch of iPhone in 2007. According to the American marketing consulting firm iSuppli, the worldwide market for touch screen devices in 2013 will be 6 billion dollars.

\subsection{The Gestural interface}

The gesture is any physical movement that the digital system can respond to without the help of any traditional devices like a mouse, for example. It may be a wave of a hand, a nod, a touch or a raised eyebrow [11]. Two gestural interface categories can be mentioned:

\subsubsection{Touch screen interface}

Require the user to touch the device directly. Also called resistive and capacitive, this technology is present on the screen of GPS and in some models of phones like the iPhone, which uses finger pressure $t$ create or change an electrical current.

3.1.2 Free-form Interface

ce

Do not require the user to touch or handle the devi ${ }^{\text {a }}$ directly. Sometimes requires the use of a control or $\mathrm{n}$ glove as input device. Also called image-recognitio $\mathrm{f}$ technology, the gesture is identified by means 0 cameras.

\section{Ergonomics and usability of electronic products}

Someone could say that ergonomics gave birth to usability because the most suitable the interactive system is, the higher levels of effectiveness, efficiency and satisfaction will be achieved by the user during system use. In fact, ISO 9241, in its part 11, defines usability based on:

-Efficacy: the capacity a system offer to different types of users to achieve their objectives in number and quality required.

-Efficiency: the amount of resources (eg time, effort, physical and cognitive) a system requires so its users can achieve their goals with the system.

-Satisfaction: The emotion users experience from the results obtained with a system and the necessary resources used to achieve its goals [7]

According to [7] cited in [9],the usability engineering tests systems or products in order to assess if they are easy to use, learn, memorize, error-free and if they bring satisfaction to the user.

\subsection{The ergonomics of the human body}

The best gestural interactions are those that combine a correct sensor with a human movement deeply engaged in the activity. It is therefore important to know what is the range of human movement and how it moves. Few designers who create medical devices or exercises are familiar with the anatomy of the human body. They do not understand that the human body is, above all, a primary input device for any gestural interface. The kinesiology is the study of anatomy, physiology and mechanisms of the human body. [10]

Knowing the major muscle movements is critical to design new products. What makes the human body to move is the joint action of muscles in action via elastic tendons to lead a bone into movement. Because of that the human body is able to perform movements such as flexion and extension, rotation, abduction, adductions, 
1526

internal and external rotation, elevation and depression, protraction and retraction, supination and pronation, plantarflexão dorsiflexion, eversion and inversion, contrast and replacement. The latest and greatest movement is a combination of several: flexion, extension, abduction and adduction: circumdiction, which is the circular motion of the body as well as wrist and eye, foot and hip rotation [9]. Such movements are important for both gestural touch screen interfaces as for free-form interfaces, since both require physical movements

\subsection{A ergonomia do gesto interativo:}

Besides Knowing the limits of the human body when creating an interface that will be controlled by itself, a Designer needs to observe the following rules:

- Observe simultaneous movements: Almost all users can touch one touch screen, but not everyone is able to swing his left hand while swinging his right leg. This requires a user to use it carefully and follow basic commands.

- $\quad$ Observe the public / user: if the gestural interface is intended to be used by regular people inside a public kiosk, for example, it should be simpler than those intended to be used by a clever teenager who will use it at home on a gaming system.

The research and experiences based on human physiology are presented in the industrial design book called Designing for people, in which $t$ is described measurements of the hands of men, women and children, shown in Figure 1.

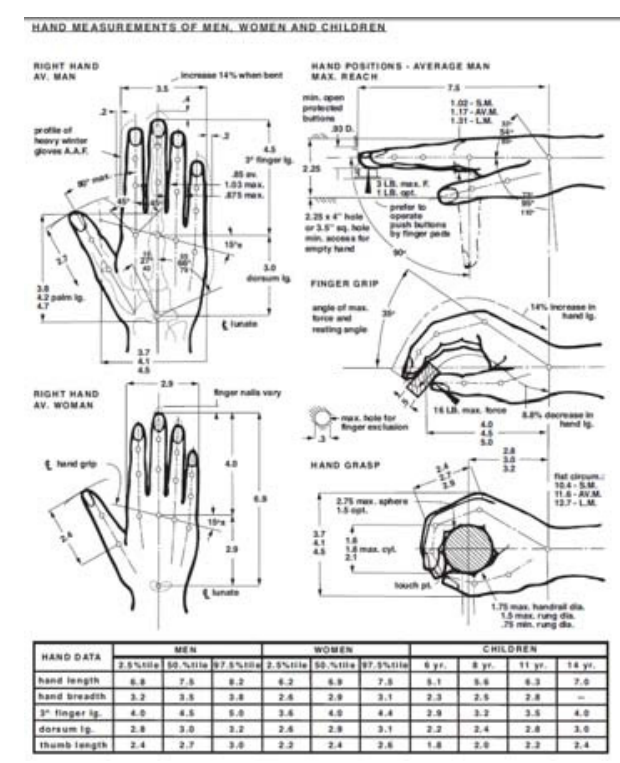

Fig. 1

The hand characteristics and registration heuristics were, in part, inspired by Henry Dreyfuss's 1955 book "Designing for People."
It is important to understand the particular forms of maneuvers carried out by human hands. The maneuvers is a particular form of control, where there is a predominance of fingers and palms. Human hands are one of the most versatile and sensitive tools of all and,

thanks to its mobility, with the thumb working in opposition to others, you can get a variety of maneuvers, with variations of power, precision and speed. In [5] are defined two types of maneuvers:

- $\quad$ fine maneuver: played with the fingertips, also called precision maneuver

- coarse maneuver: runs with the center of the hand. The fingers have to hold the function, remaining relatively static while the movements are performed by the wrist and arm.

The designer should know the body anatomically as well as ergonomically to design a gestural interface. The ergonomic principles found in [11], are as follows:

- Avoid any positions that could cause hyperextension

- avoid repetition

- relax muscles

- use neutral and relaxed positions

- Avoid staying in static position

- prevent internal and external forces in the joints

\subsection{Ergonomics in cell phone use}

It was proven in 1973 that cell phones theory worked perfectly. This was not a very well known time, but certainly one that has changed the history of the world. The first model was first marketed in the U.S. in 1983, ten years after the first test. They were not as portable as the ones we have now-a-days, due to the size and weight, as the majority were developed for car installation. In evolutionary terms, the model Handheld, named Newton, was released by Apple in 1992 and in 1996 Robotics made the release of (Palm) Pilot 1000 and 5000 which gave rise to the Palm system, still used today. Devices with Windows CE 1.0, from Microsoft, and NEC Mobile Pro 200 as Casio A-10 appeared in 1996. Until the release of Windows CE 3.0 and Pocket PC platform in 2000, the Windows CE platform had not a good market acceptance. It had better acceptance with the Pocket PC 2000 operating system, embedded in devices like the HP Jornada and Compaq iPAQ [7] cited in [1]. It was in 1998 that the company Psion and Symbian delivered to the market the Symbian operating system, which runs on most smartphones and handhelds from Nokia, which currently holds the largest market share in Europe when it comes to mobile devices. Today, the market bet is 
that the creation of equipment will focus palmtops functions as cell phone, digital cameras, Global Positioning System (GPS) and numerous other functions combined to excellent performance, large storage capacity and numerous possibilities of communication [7] cited in $[1,2]$.

\subsection{1- As CellPhone's multifunctions}

The technology focused on this explanation is the $3 \mathrm{G}$ mobile phone, which allows network operators to offer their users a wider range of advanced services as they have a greater network capacity because of an improvement in spectral efficiency. It also supports a greater number of voice and data customers, especially in urban areas, in addition to higher data rates at a lower cost than the $2 \mathrm{G}$ technology.

Within this context mobile phones have internet access, camera built-in photo and video devices, can send and receive photos and video clips besides simple text, are alarm clocks, write reminders and are capable of playing games and music. Some of them, known as Smartphones, have a Palm handheld PocketPC integrated. This technology enables connection to other phones, IrDA (infrared) or Bluetooth, serving of sending data between phones. They allow access to the internet via Wi-Fi and $3 \mathrm{G}$, and $4 \mathrm{G}$ broadband in Japan, as well as graphics games like PSP video game with 3D quality. Screens that in 2003 had 4000 colors, now have more than 16 million. Inches also increased. Today cell phones have screens with up to 4 touch sensitive inches [7]. Devices with touch screens will receive greater focus from now on. ${ }^{1}$

\subsubsection{Touch screen cell phones}

Since the iPhonelaunch in 2007 , touch screesn have spread between portable electronics. It became desirable item in smartphones, games, photo and video cameras and even personal computers. [12] Cell phones developed after the iPhone allows access to almost all functions with just one touch, allows web navigation and use of intensive image applications such as GPS and maps. Such images can be moved in all directions and zoomed in or out with a simple finger move. Figure 2 illustrates a LG cell phone model Arena, which has a menu where each row of icons move independently to the left or right.

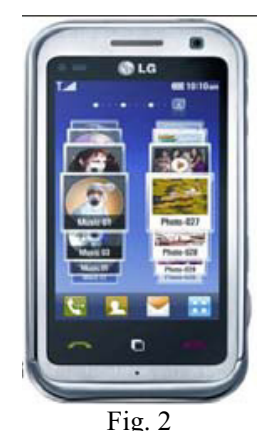

LG's Arena Touch scrren

Source: www.lge.com/br/index.jsp

The user passes a finger over them horizontally and access other applications. It has large number of preinstalled programs, such as video editors, organizers and voice recognition software. The virtual keyboard has the same configuration of a conventional phone keypad with three letters per key, which makes it difficult for typing.

Another model is the Samsung Omnia which screen has a sidebar with shortcuts to applications such as clock and calendar. To open one of them the user has to drag it with a finger to the center of the display. In Figure 3 can be seen the screen of the device, which does not always correctly interpret the touch of the finger. Therefore, it avoids the use of the pen, especially to type messages and addresses in the browser.

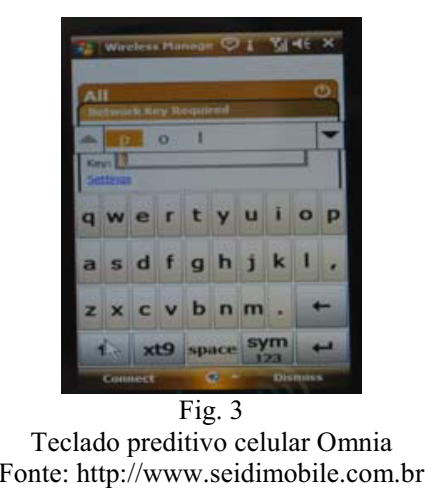

In these two examples of Touch screens mobile phones models can be observed the presence of touch screen patterns, defined in [11] as formats used with the product that user will slowly get used after purchasing it. They are defined as:

I. Play to open or activate: it is the simplest manual touch and it is equivalent to the mouse up and down movement in a conventional system.

II. Tap to select: it is simply a matter of matching the position of touch to the user in wich the user can choose an option. 
III.

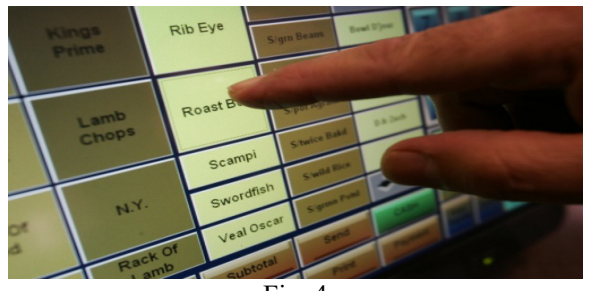

Fig. 4

Touch to select an option

Source: http://www.google.com.br/imgres

Others touch screen paterns can be maentioned:

IV. Spin to scroll: the user moves the finger in a circular motion to rotate. Used when there is a list of items as menu or the result of searches. Allow a fast rotation with a more continuous and smoother movement than up and down or side to side. An example of this pattern is seen in Figure 4 that presents an Apple iPod.

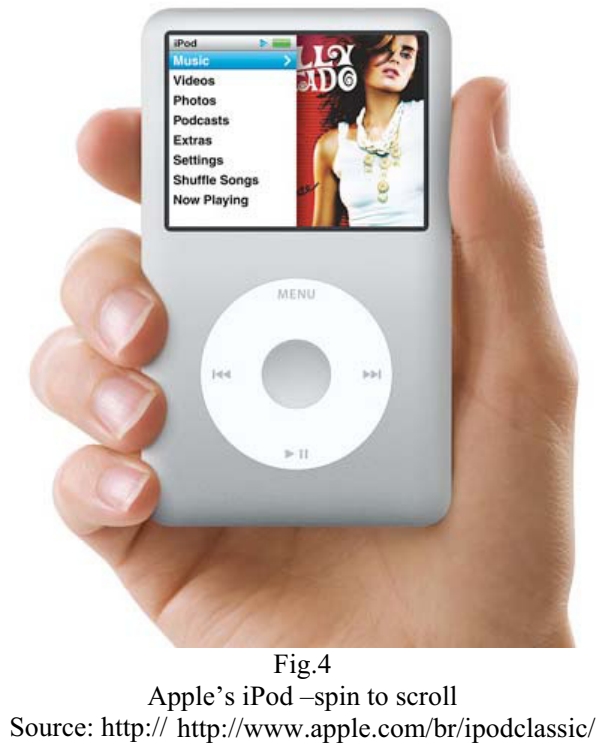

This standard requires of the user a careful choice of the speed to activate the scroll of the circle in search menu. When scrolling too fast the user may lose functions and be forced to return. Likewise, it is often difficult to select the desired function having the user to go back and forward to select what he wants. It is necessary that the User understands that the list structure is presented in alphabetical order.

\footnotetext{
${ }^{1}$ Available at: http://pt.wikipedia.org/wiki/3G

V. Slide to Scroll: a pattern similar to drag to move, but in this case the User slides a finger in one direction and the menu bar slides in another direction. Indicated when the user wants to access data with large area, long texts, large maps or data that has sought large.
}

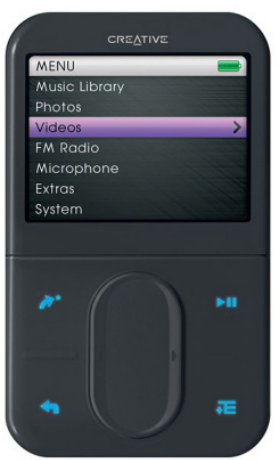

Fig. 5

Apple's iPod -spin to scroll

Source: http:// http://us.creative.com/welcome.asp

\section{Guidelines for the new design}

The design of a new product should always seek to meet a users' need. This need should be merged into the context, resources and organizational objectives in order to generate business. The designer must remember that usability is linked to the ease of use of the product. If the product is easy to use, its functions will soon be learned and memorized by the user. Add ing a maximum of functions to an electronic device is no guarantee of success. If only the basic functions of the product are assimilated by the user, the left become no longer important. In addition to asking whether a function is needed for the new product, the designer must question whether it is appropriate, as in the case of - products with gestural interface. There are a some reasons not to use gestural interface, which are described in [11]:

- Heavy data entry: some users easily adapt to touch screen keyboards, but conventional keyboards are faster to input (type) text and numbers.

Visual Reliability: many gestural interfaces use feedback only to indicate that an action was taken (like a button being pressed). If the user is an elderly person with vision difficulties the gesture interface may not be adequate. In this case has been observed that elderly public has been focus of cell phone manufacturer. Some of them have endeavored to create cell phones that fit their needs. As an example we mention Vodafones' model that uses very simple and practical applications, in order to facilitate its use to people who are not accustomed to technological language. In addition, it has on its back emergency calls buttons, whose numbers are very easy to program. 


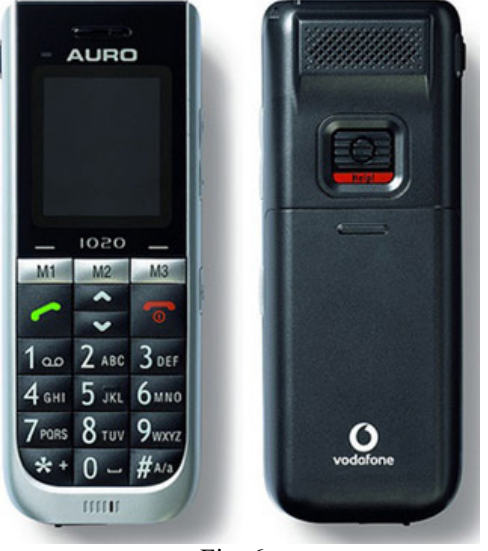

Fig. 6

Vodafones' Auro

Source: http//_www.vodafone.co.uk/

- Confidence in the physical: Gestural interface may have more physical demands than a regular keyboard. Gestural interface will be harder for an older person with illness, cold gloves. It will be easier to handle an iPhone if the user has small hands and fingers, delicate.

- Inappropriate for the context: the environment may not be consistent with a gestural interface in a numbers of situations, either due to personal reasons or to avoid embarrassment to the user. Designers should take into account the likely environment of use.

- There are some featurestBoth in the case of cell phones and other electronic devices that gestural interface should have, which are described in [6] saying that a good interface should have: - Detectable: the user should be able to detect that the screen is playable before interacting with the system. Know its affordance, which is a property objects have that indicates how the user can interact with it.

- Trustworthy: gestural interface has to be apparently competent, safe, and must respect the users' privacy. An attractive affordance should also be employed.

- Suitable: gestural system needs to be appropriate to the culture, situation and context in which it is inserted. For example, thea gesture of "okay" commonly used in North America and Western Europe is an insult in Greece, Turkey and Russia. - Meaningful: the gestural system has to have meaning for the user. If it does not macth users' nedd then it's not a good system. - Smart: devices used by humans should be quick, with a infallible memory, capable to detect complicated patterns, strong and small. - Smart: a way of being smart is through an interactive gesture that combines all about the user is trying to run. - Fun: through games, users will not only begin to engage with its interface, but will also explore new features and variations on is gestures. Users need to feel relaxed and engaged in the game. - Delightful: gestural interface should be pleasing esthetically and functionally. It must be pleasant to use, which causes good feelings in users. - Good: designers must ask themselves if the products

created are good for the users, for those who are affected indirectly to the culture and for the environment. Choices need to have vision of the future.

\section{Discussion and conclusions}

To know users needs, its body and create products that address an ergonomic usability are basic requirements for a designer to create a new product. Knowing the user means to understand it according to its cognitive, perceptual and emotional abilities so that the new product can meet its real expectations. Equipments with touch screen, which use gestural interface, are increasingly their presence in daily life. They can be seeing in kiosks, voting machines, banks and airports. It is necessary to understand the limits of the human body to propose these gestural interfaces for electronic products besides trying to find the users' real needs. Although innovative, friendly and interesting, interactive design will not be a success if it does not meet the needs of its users.

Contextualizing the product within the age group in wich it will be used by, as well as social class, is also a factor to be considered, because the ability to handle a large number of functions is greater in a teenager than in an elderly person. To Think in ergonomic usability is to worry if the products are easy to use, learn, remember, if they are free of errors and if they can bring satisfaction to its users. As guideline for a new design we suggest a multidisciplinary organization creating relevant qualities to new products.

\section{References}

[1] Abreu, L. M. ; Moraes, A. . A Usabilidade dentro do contexto de efemerização do aparelho celular. In: III Congresso de Ergonomia e Usabilidade, Design de Interfaces e Interação Humano-Computador, 2004, Rio de Janeiro. III Congresso de Ergonomia e Usabilidade, Design de Interfaces e Interação Humano-Computador, 2004.

[2] Araujo, E. C. J. ; Vieira, L. V.; Guedes, R. M. ; Coutinho, A. F. B. . Avaliação da Usabilidade de Dispositivos Móveis. João Pessoa PB: Faculdade de Tecnologia de João Pessoa, 2009

[3] Cohen, J., et al. 1999. Logjam: a tangible multi-person interface for video logging. In Proceedings of the CHI 99 Conference on Human 
Factors in Computing Systems,pp. 128-135 in Handbook of Human Factors and Ergonomics Methods, CRC press, 2004

[4] Green, S. W.; Jordan, W. Peasure with products: beyond usability. Taylor \& Francis, New York, 2005- capitulo 1

[5] Iida, Itiro. Ergonomia: Projeto e Produção. São Paulo: Edgard Blücher, 2005 pg. 243

[6] Karwowski, W. (2001),International Encyclopedia of Ergonomics and Human Factors, Vols. I-III, Taylor \& Francis, London in Handbook of Human Factors and Ergonomics Methods, CRC press, 2004

[7] Machado, L. V. Avaliação Da ergonomia E Usabilidade De Dispositivos Móveis Para Terceira Idade- Unibalsas, 2010. www. http://si.unibalsas.edu.br/wp-acesso em 21 de agosto de 2011-08-29

[8] Nielson, Jacob. Usability Engineering. San Francisco: Morgan Kaufmann, 1993

[9] Overbeeke, C.J. and Hekkert, P.P.M., 1999. Editorial. In Proceedings of the FirstInternational Conference on
Design and Emotion.Overbeeke, C.J. and Hekkert, P.P.M. (Eds), 3-5 November, Delft.

[10] Stanton, Neville et al.The handbook of human factors and ergonomics methods. Londres: CRC Press, 1960.

[11] Saffer,Dan. Designing Gestural Interface. Ed. O'Reilly:2009

[12] Revista veja. Veja digital: consumo. 12 de agosto de 2009 